\title{
Diagnosis and analysis of two king-post trusses
}

\author{
J.M. Branco \& P.J.S. Cruz \\ Civil Engineering Department, ISISE, University of Minho, Portugal
}

M. Piazza

University of Trento, Trento, Italy

\begin{abstract}
An accurate geometric and mechanical evaluation of two king-post trusses, based in grading results with data gathered from NDT as well as from mechanical evaluation, followed by full-scale tests were performed. The trusses were reassembled in laboratory and submitted to a series of cyclic tests under symmetric and asymmetric loading. Strengthening techniques evaluated in precedents research steps were used in a second phase of the carrying tests.
\end{abstract}

\section{INTRODUCTION}

The work presented here has been developed within a general research program devoted to investigate the behavior of traditional timber trusses and to identify suitable strengthening strategies. The study addresses the overall behavior of full-scale timber trusses under cyclic tests under symmetric and asymmetric loading. The carrying tests were preceded by an accurate geometric and mechanical evaluation of each timber elements of both trusses studied. Visual grading and non-destructive tests based on local and global evaluation were performed.

After the carrying tests on the unstrengthened trusses, following a load procedure according to the Service and Ultimate Limit States, the trusses were strengthened. Strengthening techniques, based in the use of metal devices, were evaluated in previous steps of the research (Branco, 2005), through full-scale tests on traditional timber connections. Strengthening aimed to improve the carrying capacity of the trusses and to analyze the influence of the joint stiffness in the overall behavior, in particular, under asymmetric loads.

\section{TRUSSES STUDIED}

The trusses studied have been recover from an old building locate at Pergine Valsugana $(20 \mathrm{~km}$ East from Trento) which will be transformed in a school. The construction is not very ancient, probably built in the first part of the last century, and did not present signs of rehabilitation or strengthening actions. The building

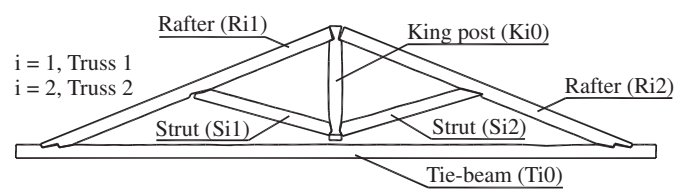

Figure 1. Trusses geometry.

is a typical rural construction with ground floor, first level and attic with visible timber roof structure. The change in the use of the building results in the necessity to remove the timber trusses. The trusses with a king-post configuration have a span near to 10.5 meters.

All members are composed by one single timber piece of Spruce (Picea Abies Karst.), presenting a mean cross-section of $20 \times 23 \mathrm{~cm}^{2}$. All members were marked before dismantling of the trusses necessary for their transportation to the Materials and Structural testing Laboratory of the University of Trento.

\section{DIAGNOSIS}

\subsection{Geometric assessment}

During the visual inspection, significant variation in cross-section geometric properties was founded. Because each component of the trusses is composed by a unique timber piece, it is normal to verify significant variability in the cross-section area of the elements, in particular in those longer like the tie beams. To have an adequate report of all those variabilities of the trusses geometry, a geometric assessment was performed. 


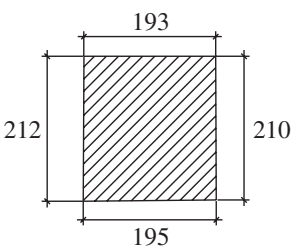

(a)

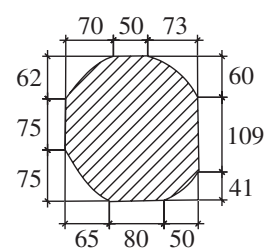

(b)
Figure 2. Comparison between the geometric properties of the cross-sections: (a) supposing rectangular and (b) with detailed measurements (dimensions in millimetres).

Table 1. Visual strength grading according to UNI 11035.

\begin{tabular}{llll}
\hline Truss & Element & Strength class & $\mathrm{E}_{0, \text { mean }}(\mathrm{MPa})$ \\
\hline 1 & $\mathrm{~K} 10$ & $\mathrm{~S} 1$ & 12000 \\
& T10 & $\mathrm{S} 2$ & 10500 \\
& $\mathrm{~S} 11$ & $\mathrm{~S} 1$ & 12000 \\
& $\mathrm{~S} 12$ & $\mathrm{~S} 2$ & 10500 \\
$\mathrm{R} 11$ & $\mathrm{~S} 2$ & 10500 \\
& $\mathrm{R} 12$ & $\mathrm{~S} 1$ & 12000 \\
$\mathrm{~K} 20$ & $\mathrm{~S} 1$ & 12000 \\
& $\mathrm{~T} 20$ & $\mathrm{~S} 1$ & 12000 \\
& $\mathrm{~S} 21$ & $\mathrm{~S} 2$ & 10500 \\
& $\mathrm{~S} 22$ & $\mathrm{~S} 3$ & 9500 \\
$\mathrm{R} 21$ & $\mathrm{~S} 1$ & 12000 \\
$\mathrm{R} 22$ & $\mathrm{~S} 1$ & 12000 \\
\hline
\end{tabular}

Each element, every $40 \mathrm{~cm}$, was marked, named and the cross-section measured. Figure 2 presents the cross-section A of the tie beam of the Truss 1, as example of the difference that can be obtained if an inadequate measurement of the cross-section is done.

\subsection{Visual grading}

The grading criteria according to the European (EN 518:1995) and the Italian national standards (UNI 11035-1-2:2003) have been applied. The species of the two king-post trusses analyzed is Spruce (Picea Abies Krast.), from North Italy, accordingly, grading criteria referred to the group 'softwood 1' (conifere 1) in UNI $11035 \S 5.3$ have been adopted. For visual grading, it was necessary to record the moisture content and to calculate density.

\subsection{Non-destructive tests (NDT)}

Non-destructive tests based on local and global evaluation of the material were performed. Resisting drilling obtained by means of the Resistograph ${ }^{\circledR}$ device, the penetration depth achieved with the Pilodyn ${ }^{\circledR}$ and the hardness Turrini-Piazza tests results are examples of techniques based on local evaluation. After, global evaluations methods were conducted: Sylvatest, using ultrasonic waves, and the mechanical evaluation of the modulus of elasticity.

\subsubsection{Hardness tests}

In the Turrini-Piazza tests, hardness is estimated by measuring the load force $R$ required to embed a $10 \mathrm{~mm}$ $\phi$ steel hemispherical bit to $5 \mathrm{~mm}$ (Turrini \& Piazza, 1983). The value of $R$ was obtained by averaging the tests results made in the four longitudinal faces of the element, in numbered sections every $80 \mathrm{~cm}$ wide. Each test consisted in five measures taken in each tested area. The result of each test was obtained by averaging the three middle values among the five measures. It means that, for each considered section: 9 for the tie beam, 5 for the rafters and 2 for the struts and king post; twenty tests were done (four by surface). At the end, nearly 1000 hardness tests were performed. The correlation between $R$ and elastic modulus in longitudinal tension $E 0$ is expressed by the experimental equation:

$E_{0}=\delta \cdot 350 \cdot R^{0.5}$

where $\delta$ indicates a reduction factor, $0.5 \leq \delta \leq 0.8$, that depends on the defectiveness of the element.

Because the Equation 1 is experimentally founded, its reliability depends on the limits of the experimentation itself: namely on the species of the tested samples that are Silver fir (Abies Alba) and Larch (Larix decidua), on loading conditions $(700 \div 3000 \mathrm{~N}$ ) and moisture content in the range $12 \%-14 \%$. However, due to the large amount of hardness test performed and since mechanical determination of the elastic modulus of some elements (tie-beams and rafters) is available, it was possible to calibrate the equation for the case $o$ Spruce (Picea Abies Karst.). The value of $\delta=0.6$ was founded. After the calibration of the $\delta$ value, it was possible to calculate the elastic modulus of all elements that compose the two king post trusses.

\subsubsection{Pilodyn}

The Pilodyn method uses a steel pin of a fixed diameter driven into the material by a dynamic force. The depth of penetration is correlated with material density. Görlacher (1987) and Feio (2005) developed relationships between the depth of penetration of a standard pin and the density of the wood. Those correlations depended on the number of measurements, species and are affected by moisture content. For all elements that compose both trusses, in each section used for the geometric assessment, the penetration depth obtained by the Pilodyn in the 4 faces, was measured. Table 2 summarized the Pilodyn tests results obtained.

\subsubsection{Resistograph}

The use of a small-diameter needle-like drill was introduced by Rinn (1992). The cutting resistance of a 
Table 2. Depth penetration means values for Pilodyn.

\begin{tabular}{lcclc}
\hline Element & $\begin{array}{l}\text { N. }{ }^{\circ} \text { of } \\
\text { measurements }\end{array}$ & w (\%) & $\begin{array}{l}\text { Density } \\
\left(\mathrm{kg} / \mathrm{m}^{3}\right)\end{array}$ & $\begin{array}{l}\text { Depth } \\
(\mathrm{mm})\end{array}$ \\
\hline K10 & 20 & 11.7 & 450 & 16.25 \\
T10 & 104 & 12.2 & 478 & 10.41 \\
S11 & 24 & 11.5 & 432 & 19.63 \\
S12 & 24 & 11.3 & 410 & 20.42 \\
R11 & 52 & 12.5 & 467 & 12.38 \\
R12 & 48 & 11.9 & 460 & 11.98 \\
K20 & 20 & 12.7 & 457 & 13.10 \\
T20 & 104 & 12.4 & 432 & 15.68 \\
S21 & 24 & 12.2 & 384 & 21.42 \\
S22 & 24 & 12.3 & 450 & 10.75 \\
R21 & 52 & 12.8 & 479 & 11.54 \\
R22 & 52 & 12.1 & 447 & 13.62 \\
\hline
\end{tabular}

needle is recorded as a function of depth as the needle penetrates the timber. The resulting profile can be used to determine the location and extent of voids and variation in material density. This technique is highly effective for quantifying the extent of deterioration in timbers. Some researchers (Feio 2005, Frankl et al. 2006, Kotlínová et al. 2007) have tried to use the results of the resistograph as prediction of the mechanical properties. For that, he used the Resistance Measure (RM), given by the quotient between the integral of the area of the resistograph chart and the depth penetration of the nail in the specimen:

$R M=\frac{\int_{0}^{\text {depth }} \text { Area }}{\text { depth }}$

However, the use of the RM value to estimate mechanical properties is questionable (Lear, 2005). The area of a resistance-drilling plot can be affected by multiple parameters including drill bit sharpness and general equipment use such as drill orientation. On a single member, changes in the orientation of the drill with respect to growth rings will change the calculated RM value with each drilling.

\subsubsection{Sylvatest}

The ultrasound device Sylvatest ${ }^{\circledR}$ allows sending and receiving longitudinal ultrasound waves using two piezoelectric probes. It measures the duration of the stress wave course in the tested sample, with regard to its moisture content and temperature, which are also controlled. Since there is a one-to-one relation between this speed and the mechanical quality of timber (elasticity modulus and, less significant, resistance), the instrument displays directly the measured mechanical quality after the evaluation of the influence of wood
Table 3. Sylvatest results using the direct method.

\begin{tabular}{lllllll}
\hline & $\begin{array}{l}\mathrm{w} \\
\text { Element } \\
(\%)\end{array}$ & $\begin{array}{l}\text { Length } \\
(\mathrm{m})\end{array}$ & $\begin{array}{l}\text { Time } \\
(\mu \mathrm{s})\end{array}$ & Class & $\begin{array}{l}\mathrm{E} \\
(\mathrm{MPa})\end{array}$ & $\begin{array}{l}\mathrm{Fb} \\
(\mathrm{MPa})\end{array}$ \\
\hline K10 & 11,7 & 1,88 & 329 & 0 & 13200 & 18 \\
T10 & 12,2 & - & - & - & - & - \\
$\mathrm{S} 11$ & 11,5 & 2,23 & 400 & 1 & 12200 & 12 \\
$\mathrm{~S} 12$ & 11,3 & 2,23 & 393 & 1 & 12800 & 16 \\
$\mathrm{R} 11$ & 12,5 & 5,1 & 850 & 0 & 15400 & 28 \\
$\mathrm{R} 12$ & 11,9 & 4,85 & 869 & 1 & 12200 & 12 \\
$\mathrm{~K} 20$ & 12,7 & 1,87 & 315 & 0 & 14600 & 24 \\
T20 & 12,4 & - & - & - & - & - \\
S21 & 12,2 & 2,32 & 400 & 0 & 13600 & 20 \\
S22 & 12,3 & 2,42 & 459 & 3 & - & - \\
R21 & 12,8 & 5,1 & 864 & 0 & 14400 & 28 \\
R22 & 12,1 & 5,11 & 824 & 0 & 15600 & 30 \\
\hline
\end{tabular}

moisture content in the element taken into consideration. The results are given in the form of quality classes or mechanical values, indicating the elastic modulus and the allowable bending strength of the element (Sylvatest, 1991).

Two measurement methods have been used: the direct method, where the transmission of the wave is done along the fibers and the indirect method, where wave transmission is across the fibers. To assess the influence of the test method on the results, both methods were applied whenever possible. Each single measured value represents the third reading value, to avoid bigger variability in the test results.

Different measurement method led to different Sylvatest results. Even using the indirect method in two different longitudinal faces, between the same sections, some results inconsistency has been found. This discrepancy is more evident in the allowable bending strength, less important for the elastic modulus in bending and disappears for the measured mechanical quality class. Table 3 summarized the Sylvatest results obtained using the direct method, when possible, for all elements component the two trusses.

\subsubsection{Mechanical evaluation of the modulus of elasticity in bending}

The stiffness of the elements, which is normally expressed as MoE (modulus of elasticity) was determined by means of bending tests. MoE for timber contains not only information about the clear wood strength properties, but also to a large extent about defects affecting the stiffness. Hence, results of bending tests have been used in this research to assess the reliability of visual grading and NDT results. Static bending tests were carried out in accordance with the four-point loading method, with reference to EN 408:2004. The relevant static scheme is characterized 
Table 4. Elastic modulus (MoE) obtained by means of four-point bending tests.

\begin{tabular}{ll}
\hline Element & MoE $(\mathrm{MPa})$ \\
\hline T10 & 12980 \\
R11 & 11149 \\
R12 & 11367 \\
T20 & 12929 \\
R21 & 12646 \\
R 22 & 12863 \\
\hline
\end{tabular}

by a constant bending moment zone and a maximum shear-to-bending moment ratio. This test uses a simply supported piece with a span of 18 times the depth, with the loading points placed on the third of the span. Because of the large span needed for the correct execution of the bending tests (18 times the depth), only the rafters and the tie-beams were tested. Results of the four-point bending tests are reported in Table 4.

\subsubsection{Analysis and discussion of NDT results}

Using UNI 11035 standards it was possible to visual strength grade the timber trusses. In particular, a strength class was assigned and a mean value for the modulus of elasticity (MoE) was suggested. Three values for MoE were founded: $12000 \mathrm{MPa}, 10500 \mathrm{MPa}$ and $9500 \mathrm{MPa}$ corresponding to strength class S1, S2 and $\mathrm{S} 3$, respectively. For visual grading, it was necessary to record the moisture content and to calculate density.

During the visual inspection, significant variation in cross-section geometric properties was founded. Turrini-Piazza hardness test permits the correlation between the load force $(\mathrm{R})$ required to embed a steel bit into the wood with MoE. However, the evaluation of a reduction factor dependent on the defectiveness of the element is required. This reduction factor was calibrate (with a value of 0.6) using near 1000 tests results and the MoE values obtained with the mechanical evaluation. Apart this capability of the test, it was tried to correlate the load force $(\mathrm{R})$ with the density. The correlation obtained is poor $\left(\mathrm{r}^{2}=0.35\right)$ despite the significant values used. Others researchers have tried to correlate the Resistance Measure (RM), obtained with the resistograph test, with density. The same attempt was made but the correlation obtained is very poor $\left(\mathrm{r}^{2}=0.02\right)$. A correlation coefficient of 0.5 was obtained for the correlation between the depth of penetration measured with the Pilodyn and the density. In conclusion, and assuming as reference values for the MoE the results of the mechanical tests, a correlation between all non-destructive tests able to predict this property and that values were defined, and presented in Figure 3.

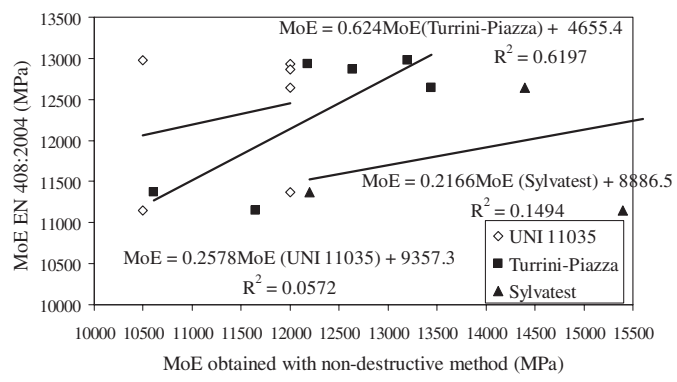

Figure 3. Correlation between $\mathrm{MoE}$ given by non-destructive test and MoE given by the mechanical evaluation.

\section{CARRYING TESTS}

The trusses were subjected to cyclic tests, under symmetric and asymmetric loading for two levels of loads corresponding to the Service and Ultimate Limit States. In consequences of their behavior under this series of tests, the trusses were strengthened. Later, the same sequence of tests was carried out over the strengthened trusses. If, after that, the failure of the truss was not been achieved, a final test under growing loading was performed.

\subsection{Test setup, instrumentation and procedure}

The timber trusses were tested under cyclic loading subjected to two point loads, each one directly applied over the joint strut-rafter. Symmetric and asymmetric tests were performed using two values of load, corresponding to Service and Ultimate Limit states (SLS and ULS, respectively). As loads, and in accordance with the Italian code D.M. 14/9/2005, it was considered the self-weight of the original timber roof and the snow load corresponding to the place were the trusses were recovered, Caldonazzo Lake (500 $\mathrm{m}$ of altitude). Before carrying the tests, and after the reconstruction of the disassembled trusses, trusses were subjected to a series of loading and unloading tests with the aim to adjust all trusses elements together reducing to the minimum the initial gaps between them. The first step of the tests was the application of the load corresponding to the self-weight of the timber roof (covering material and structure plus purlins). After that, the remaining load corresponding to each loading case was divided in four steps. Therefore, the load target was reached after 4 cycles of loading and unloading keeping constant the minimum load applied corresponding to the self-weight. For each test, three loading cycles were applied, Figure 4.

The asymmetric tests were carried out with the asymmetric values of the snow load, as considered in the above mentioned D.M. 14/9/2005. During the tests 


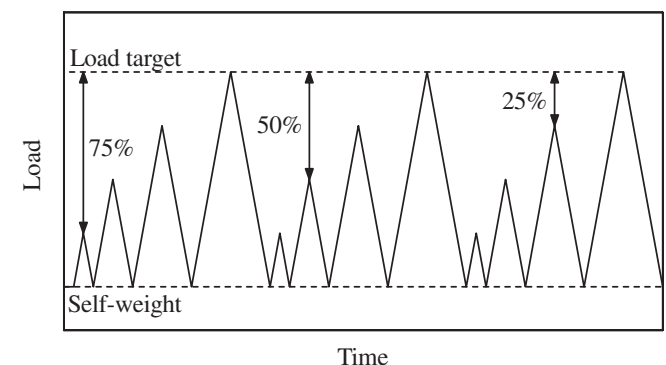

Figure 4. Load procedure applied in the carrying tests.

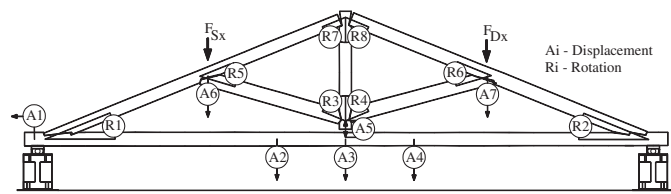

Figure 5. Instrumentation layout.

the main global displacement of the trusses, the relative displacements between the king post and the tie beam and the rotation of each joint were measured, using sixteen transducers, Figure 5.

Two hydraulic jacks, supported by a steel counterframe fixed to the reaction slab of the laboratory, were used for applying the loads. As boundary conditions, two supports restraining the vertical displacement and the right support restrained also the horizontal movement were applied.

\subsection{Evaluation of the trusses behavior}

The response of the timber trusses under the carrying tests performed is highly depending of the variability, previously detected and reported, along the truss members in terms of cross sections area and principal moments. Moreover, it is recognized the difficulty associated with tests over existing structures, in which the members can present residual deformations and signs of decay and/or the connections are not well tight. The tests results shows that even under symmetric loading conditions, the behavior of both trusses is asymmetric. This conclusion is more evident in the response of Truss 1 under symmetric loading corresponding to SLS, Figure 6.

The connection between the king-post and the tie beam, made by a steel rod of $20 \mathrm{~mm}$ diameter fixed in the king-post, aligned in the longitudinal direction, passing through the tie beam, with a nut at one end, fastening the two elements, performs adequately. The king post suspends the tie beam, Figure 7 .

As a consequence of the truss deformations under the vertical loads applied, horizontal displacement at the free support was recorded, Figure 8.

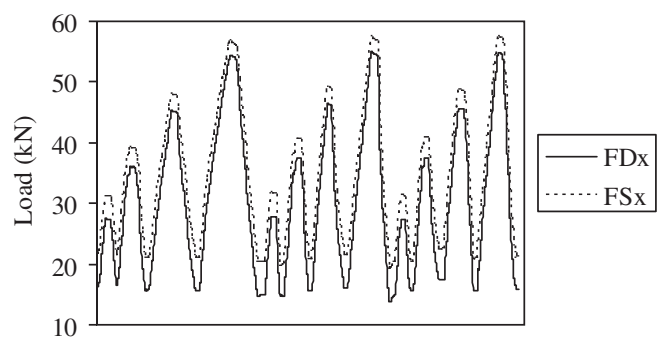

(a) Symmetric loading history

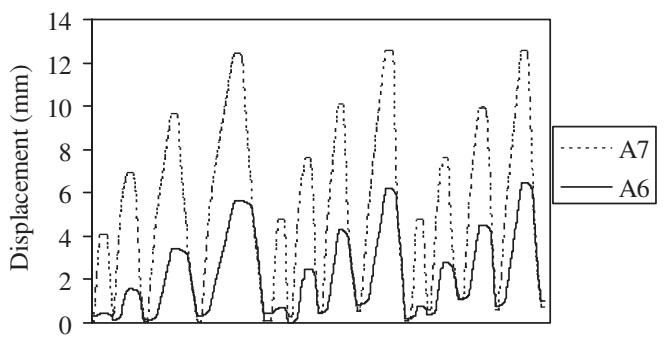

(b) Asymmetric response of channels A6 and A7

Figure 6. Asymmetric behavior of Truss 1 under symmetric loading condition (SLE).

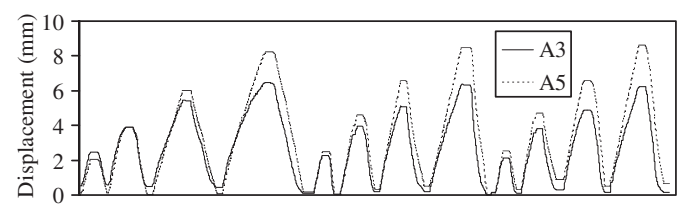

Figure 7. Behaviour of the connection between the king-post and the tie beam under symmetric loading conditions.

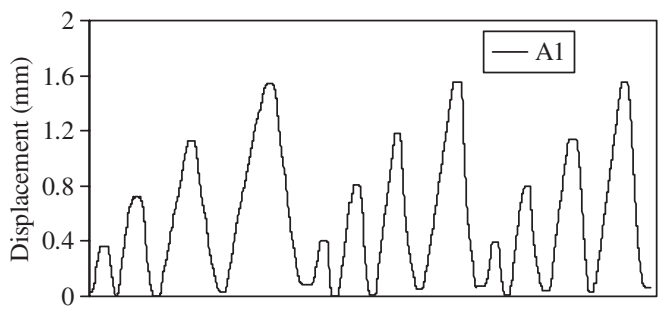

Figure 8. Horizontal displacement recorded in the support under symmetric loading.

Under asymmetric loading conditions, the asymmetric behavior of the trusses, already pointed out, is emphasized. Channels A6 and A7 shows asymmetric displacement, Figure 9.

This asymmetric behavior of the trusses introduces bending stresses in the rafters and tie beam. Because of the rotational stiffness offered by the king-post/tie 


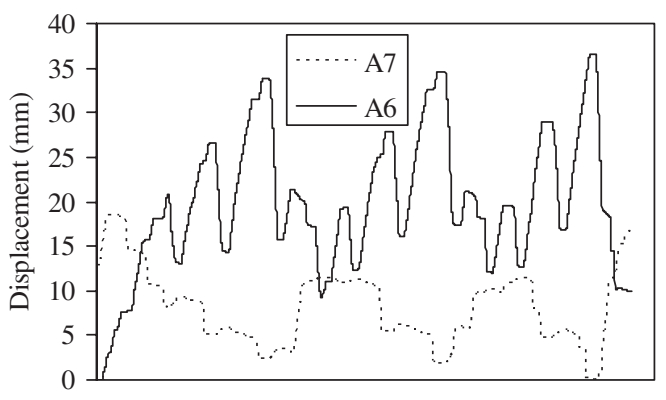

Figure 9. Asymmetric behavior emphasized under asymmetric loading (Truss 1 and SLE)

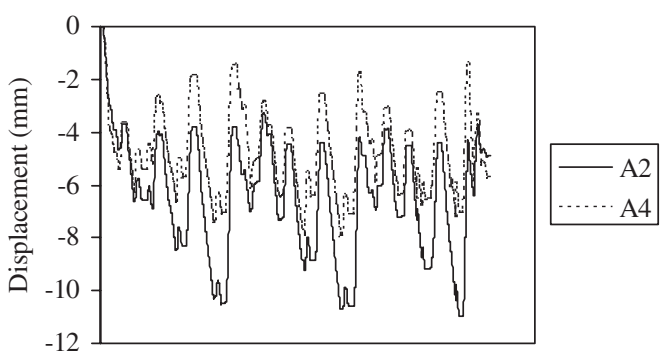

Figure 10. Distortion of the tie beam under asymmetric loading (Truss 1 and SLS).

beam connection, the asymmetric response of the overall truss causes distortion in the tie beam (Figure 10). This distortion induces important bending stresses in the bolt of that connection (Figure 11a).

The connection between the king-post and the tie beam presents rotational stiffness in the plane of the truss and in the normal plane. Therefore, this connections prevent also the out-of-plane movement (Figure 11b) improving consequently the stability of the substructure composed by the rafters, the king-post and the struts.

As expected, under asymmetric loading the relative displacement between the king-post and the tie beam, measured in the connection between both elements, is nearly zero. In addition, the horizontal movement recorded in the unrestraint support is reduced.

For the case of the Ultimate Limit State (ULS), different behaviors were observed for both tested trusses. While Truss 2 was able to perform all tests (symmetric and two asymmetric), in Truss 1 only the first cycle of the symmetric tests was achieved. When the maximum load corresponding to this limit state was reached, considerable out-of-plane movements were visible, Figure 12. To prevent the global failure of the truss it was decided to stop the test and to strength Truss 1 before proceeding with the experimental program.

In the case of Truss 2, the tests undertaken for SLS were repeated for the load level corresponding to the

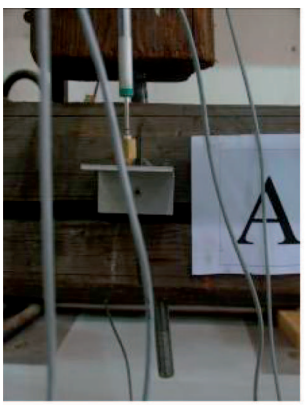

(a)

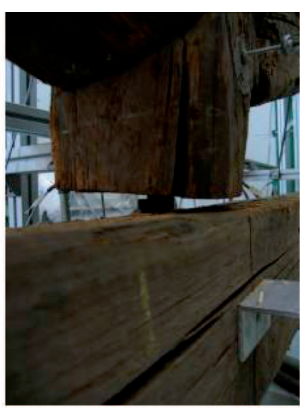

(b)
Figure 11. Behavior of the king-post/tie beam connection: (a) in plane bending of the bolt (b) out-of-plane movement prevented.

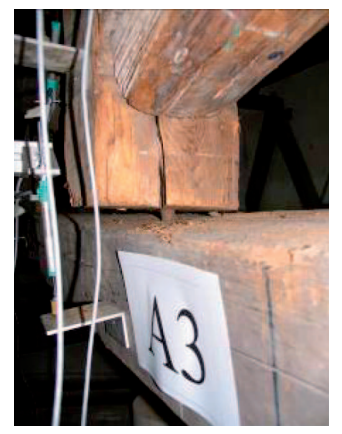

Figure 12. Out-of-plane movement observed in the truss 1 (unstrengthened) under ULS at the end of 1 st cycle.

ULS. The main conclusion about the overall behavior of the truss pointed out for the SLS can be extended to ULS. Therefore, it can be concluded that, apart from the instability observed in the case of Truss 1 , the safety of the trusses under the Ultimate Limit States was verified. No local collapse or failure in the timber members occurred. The bracing forces transmitted by the purlins and the covering structure should prevent the instability observed in the case of Truss 1 .

\subsection{Strengthening}

The next phase in the experimental program was to strength the trusses based in the response obtained in first phase and to repeat the tests. Strengthening of Truss 1 aimed essentially to repair the out plane movement observed and to prevent this instability making possible to perform the carrying tests corresponding to the ULS. The out plane deformations were removed and a UPN profile was bolted to the king-post. The objective was to prevent the out plane movements, increasing the stiffness of the connection in this direction, keeping the tie beam suspended to the king post, 

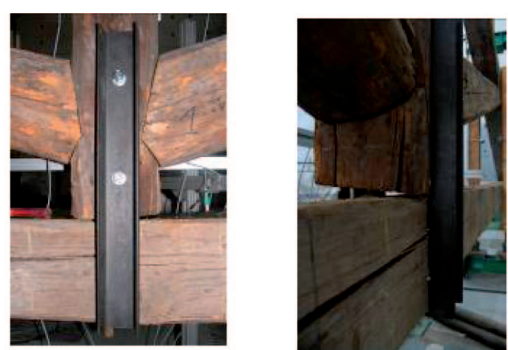

a) UPN profile preventing the out plane movements in the king-post/tie beam connection

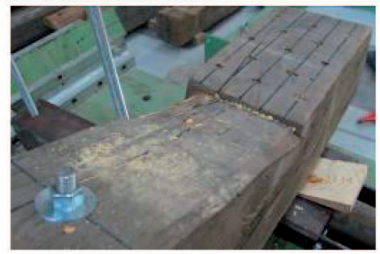

b) Screws and internal bolt to strength the rafter/tie beam connection

Figure 13. Strengthening of Truss 1.

Figure 11a. The timber elements did not presented any local failure or damage however, the connections between the rafters and the tie beam were weakened. In particular, the left connection, over the support with horizontal displacement, the depth step was insufficient and the timber beyond the step was fissured. Then, it was decided to strength this part of the tie beam (beyond the step) with screws (12 screws M6200) aiming to increase its shear resistance. Moreover, using the existing holes, an internal bolt of $20 \mathrm{~mm}$ diameter was introduced at midjoint and normal to the rafter in each rafter/tie beam connection, Figure 12b.

In the case of Truss 2 , only the connections between the rafters and the tie beam were strengthened. The stiffness of the king-post/tie beam connections demonstrated to be adequate to prevent the out-of-plane instability. Rather, the timber beyond the step demonstrated some signs of deterioration and the depth of the steps in the rafters/tie beam connections looked insufficient. In this last case, the same strengthening technique used before in Truss 1 was applied: one internal bolt tightening the connection and screws beyond the step to improve the shear resistance. However, and as an improvement based in the failure modes observed in Truss 1, a binding strip was used to confine the timber, Figure 13

\subsection{Efficiency evaluation of the strengthening}

The series of tests corresponding to the Service Limit States (SLS) were repeated after strengthening the trusses. The main objective was to analyze the

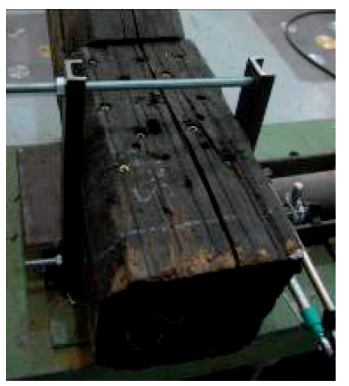

Figure 14. Strengthening of Truss 2. Screws and binding strip applied in the frontal part of the step in the rafter/tie beam connection.

influence of the joint stiffness, in this case, the stiffness of the rafter/tie beam connection, in the overall behavior of the truss in particular under asymmetric loads. However, the main goal of the strengthening was to increase the truss resistance: to make Truss 1 able to perform all load procedures corresponding to ULS, and to assess the failure load of Truss 2.

Load capacity of Truss 1 was improved by the strengthening, but only the symmetric test corresponding to the ULS was accomplished. At the end of this test, the local damages in the rafters/tie beam connections not permitted the execution of the asymmetric tests. It was decided to perform a test until failure. It is important to point out that the ultimate load achieved in the failure test is lower than the load level attained in the ULS test. Despite the strengthening measures undertaken to improve it, the failure was caused by lack of shear resistance of the tie beam beyond the step. Theoretically, the screws should increase the shear resistance but, because of the fissures already existing before placing the screws, the timber part beyond the step did not work as a rigid body. The screws expanded the fissures and the rigid body became separate in small pieces, Figure 14a. However, it is important to point out that this behavior was also accentuated by the previous shear failure of the rear step, Figure 14b. With the horizontal movement of the rafter in the connection rafter/tie beam, the joint king-post/struts was dismantled, Figure $14 \mathrm{c}$, and important bending stresses are introduced in the internal bolt, Figure 14d.

In the case of Truss 2, it is difficult to conclude if the strengthening was efficient in the increase of the load capacity of the truss as no failure was obtained in the previous tests performed in unstrengthened conditions. The strengthened truss was subjected to the full loading history foreseen in the test procedure (SLS and ULS, under symmetric and asymmetric loads). After that, a loading procedure until failure was followed. This procedure is similar to the previous one but now, the load increment did not stop at the value of $80 \mathrm{kN}$ (maximum load corresponding to ULS). 

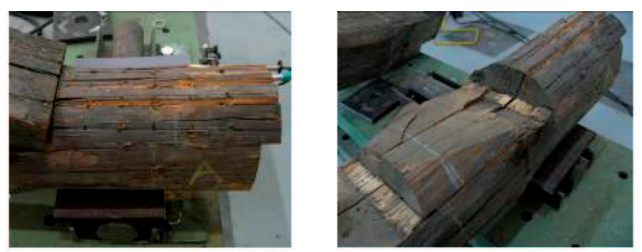

a) Shear failure beyond the step
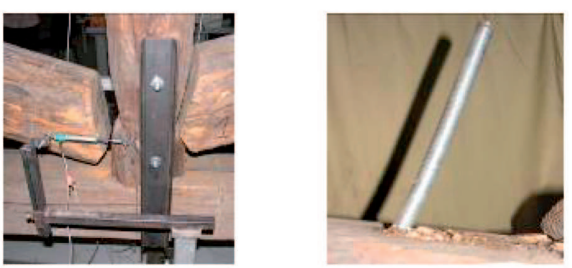

c) Disassemble of king-post/struts joint d) Bending of the internal bolt

Figure 15. Failure damages of Truss 1.

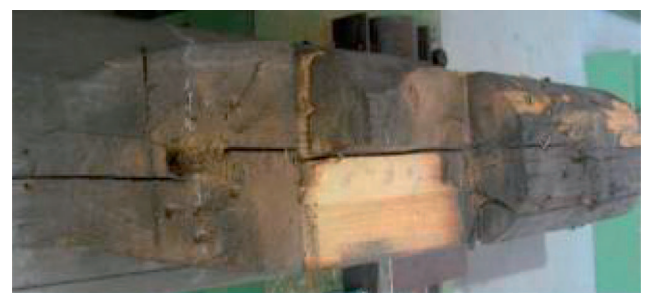

Figure 16. Shear failure of the rafter/tie beam connection for Truss 2 .
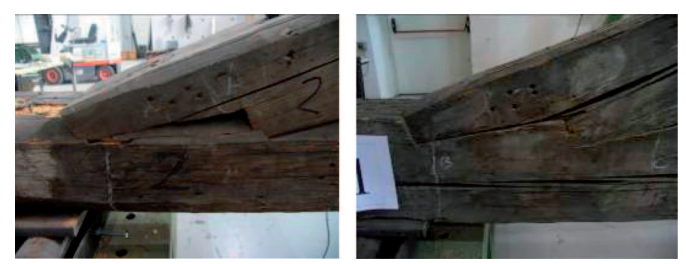

Figure 17. Double step connections between the rafters and the tie beam of Truss 2 .

The maximum load value achieved during the tests at failure was $\approx 100 \mathrm{kN}$.

Again, the failure of the truss was obtained by shear failure in the timber beyond the step in the connection rafter/tie-beam. First, the shear failure of the rear step happened and then the shear failure of the timber beyond the frontal step took place, Figure 15. The geometry decided which connections rafter/tie beam failed. The failure happens in the double step connection in which the rear step presented a faulty geometry. The rear step must be deeper than the frontal. If not, the surface resisting to shear stresses is insufficient. The double step connections of the right side (over the fixed support) failed as a consequence of a first shear failure in the rear step.

Once the rear step fails, the stresses concentrated in the frontal step and the failure is reached, Figure 16.

\section{CONCLUSIONS}

In this work, after a detailed geometric assessment of both trusses, the grading criteria according to Italian standards (UNI 11035-1:2003 and UNI 110352:2003) have been applied. As keys parameters for visual grading and non-destructive evaluation, moisture content and density were measured and recorded. After, some non-destructive techniques based on local evaluation of the material were performed. Resisting drilling obtained with the Resistograph, the penetration depth achieved with the Pilodyn and the hardness Turrini-Piazza tests results were correlated with the density values. In a second phase, global evaluations methods were used. Sylvatest, using ultrasonic waves, and the mechanical evaluation of the modulus of elasticity were performed. Some correlations between different test results, in particular, for the prediction of the modulus of elasticity (MoE) were established. Assuming as reference values for the $\mathrm{MoE}$ the results of the mechanical tests, the Turrini-Piazza Hardness test show to be a sufficiently accurate non-destructive technique in the prediction of the MoE.

The response of both trusses under the carrying tests performed is highly depending of the variability along the truss members in terms of cross sections area and principal moments. Test results show that even under symmetric loading conditions, the behavior of both trusses is asymmetric. The connections between the king post and the tie beam must ensure the adequate stiffness to avoid the out-of-plane instability of the structure. Strengthening, realized with metal devices, was able to improve the carrying capacity of the trusses. The failure of the trusses always happened for the shear failure in the rafter/tie beam connection. The failure depends of the geometry of the double step. A faulty geometry accelerates the failure. It was founded that the strengthening of wood in the frontal step with screws could be improved by confining this part.

\section{ACKNOWLEDGMENTS}

The first author gratefully acknowledges the Portuguese Foundation for Science and Technology, for his $\mathrm{PhD}$ grant SFRH/BD/18515/2004. The research described in this paper was conducted with financial support of the Portuguese Foundation for Science and Technology (POCI/ECM/56552/2004). This work 
has been carried out with a partial financial contribution of the Italian Earthquake Engineering Laboratory Network (RELUIS), within the research program carried out for the Italian Agency for Emergency Management.

\section{REFERENCES}

Branco J.M., Cruz P.J.S., Piazza M. \& Varum H. 2005. Experimental Analysis of Birdsmouth Joints. Report E-11/05. DECivil, University of Minho, $49 \mathrm{pp}$.

EN 408 2004. Timber structures. Structural timber and glued laminated timber. Determination of some physical and mechanical properties. CEN European Committee for Standardization.

Feio A.O. 2005. Inspection and Diagnosis of Historical Timber Structures: NDT Correlations and Structural Behaviour. PhD Thesis, University of Minho.

Frankl J., Kloiber M. \& Bryscejn J. 2006. Non-destructive inspection of a historical wooden structure damaged by fire. In Engineering mechanics 2006, Svratka, zech Republic, 2006, pp. 62-63.
Görlacher V.R. 1987. Zerstörungsfreie Prüfung von Holz: ein in Situ Verfahren zur Bestimmung der Rohdichte. Holz als Roh- und Werkstoff, Vol.45, No.7, 273-278.

Kotlínová M., Kloiber M., Vasconcelos G., Lourenço P.B. \& Branco J.M. 2007. Non-destrcutive testing of wood structures. Report E-12/07. DECivil, University of Minho, $63 \mathrm{pp}$.

Lear G.C. 2005. Improving the assessment of in situ timber members with the use of non-destructive and semi-destructive testing techniques. M.S. Thesis - North Carolina State University, Raleigh, 137 pp.

Rinn F. 1992. Chancen und Grenzen bei der Untersuchung von Konstruktionshölzern mit der Bohrwiderstandsmethode. Bauen mit Holz, (9)

Sylvatest 1991. Sylvates user's manual. Cableries \& Trefileries de Cossonay SA. Switzerland. $19 \mathrm{p}$.

Turrini G. \& Piazza M. 1983. Il recupero dei solai in legno. Esperienze e realizzazioni. In Recuperare, Vol. 7.

UNI 11035-1 2003. Structural timber - Visual strength grading for Italian structural timbers: terminology and measurement of features. UNI - Milano, Italy.

UNI 11035-2 2003. Structural timber - Visual strength grading rules and characteristics values for Italian structural timber population. UNI - Milano, Italy. 